\title{
Expression of Receptor Activator of Nuclear - Kappa $\beta$ Ligand in Patients with Metastatic Bone Disease
}

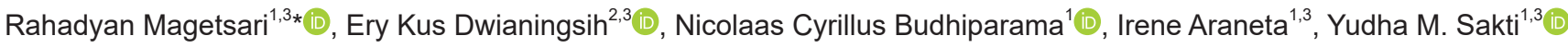 \\ ${ }^{1}$ Department of Orthopaedics and Traumatology, Faculty of Medicine, Public Health and Nursing, Universitas Gadjah Mada, \\ Yogyakarta, Indonesia; ${ }^{2}$ Department of Anatomical Pathology, Faculty of Medicine, Public Health and Nursing, Universitas \\ Gadjah Mada, Yogyakarta, Indonesia; ${ }^{3}$ Dr. Sardjito General Hospital, Yogyakarta, Indonesia
}

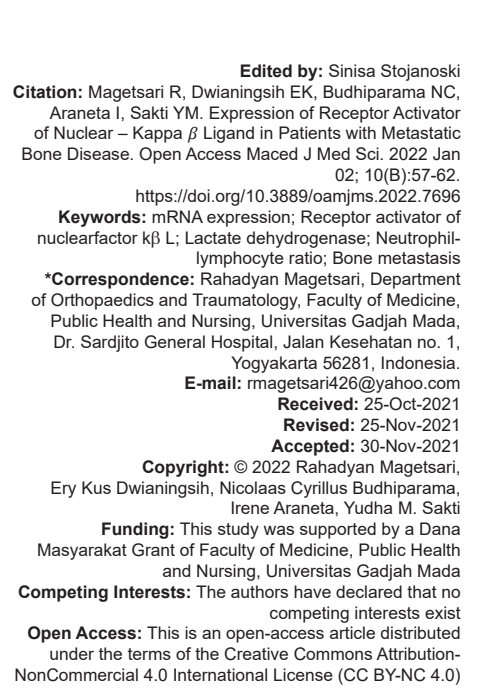

Abstract

BACKGROUND: Bone metastasis is a complication that often occurs due to cancer in solid organs, and more often compared to primary bone tumors. Bone metastasis is associated with excessive osteolytic processes

AIM: This study was conducted to reveal the correlation between Receptor Activator of Nuclear factor $\mathrm{k} \beta$ Ligand (RANKL) expression, lactate dehydrogenase (LDH), and neutrophil-lymphocyte ratio (NLR) level in patients with bone metastatic lesions.

METHODS: This cross-sectional study was conducted in 15 subjects with bone metastatic lesions. The specimens were fresh bone tissues obtained by open biopsy. Expression of RANKL in mRNA level was detected quantitatively using reverse transcription-polymerase chain reaction. LDH and NLR were analyzed from the peripheral blood analysis. The correlation of RANKL expression with LDH and NLR was statistically analyzed.

RESULTS: This study enrolled 15 subjects with bone metastasis disease based on the clinical, radiological, and histopathological results. The means of LDH, NLR, and RANKL expression were not significantly different. There was no significant association between the characteristics of metastatic lesion and RANKL expression. The correlation between LDH levels with RANKL expression was positive $(p<0.05)$, while the correlation between NLR and RANKL expression was negative $(\mathrm{p}<0.05)$.

CONCLUSION: RANKL expression was positively correlated with LDH and negatively correlated with the NLR. Both $\mathrm{LDH}$ and NLR can be used as predictive factors of RANKL expression in bone metastasis.

\section{Introduction}

Metastatic bone disease (MBD) cases are more common than primary bone tumors [1]. Bone metastasis is the third most common cause after metastasis to the liver and lungs. For example, in patients with breast or prostate cancer with an advanced disease process, $70 \%$ of cases come to the hospital already with the condition of bone metastasis [2], [3]. In the United States, about 35,000 cases/year with bone metastasis have a poor prognosis [4].

Bone metastases are associated with excessive osteolytic processes which lead to bone destruction and have an effect on significant bone morbidity, including pathological fractures and compression of the spinal nerves [5]. The pathophysiology underlying bone metastases, apart from the malignancies underlying osteolytic, osteoblastic, or mixed radiographic appearance, includes local pathological enhancement of bone remodeling processes including increased osteoclast activity [6], [7]. Evidence from other studies shows that tumor cells interact in the bone to stimulate the Receptor Activator of Nuclear factor $\mathrm{k} \beta$ (RANK)- RANK Ligand (RANKL) system, increasing RANKL expression and lead to the increase of osteoclast activity and bone destruction [6]. Additional data indicated that RANKL can play a role in primary tumorigenesis and metastasis [5].

Strategies for therapy in cases of bone metastasis are developing. RANKL inhibition is a potential therapeutic target in cancer cases, especially in bone metastases, by reducing the process of osteolysis/resorption of bone and the progression of the development of bone metastases, thereby increasing survival [8], [9], [10]. RANKL also has been associated with better therapeutic response. In a study involving patients with solid organ malignancies that had metastasized to the bone, it was found that an increase of 1 unit of RANKL would escalate 2.5 times the likelihood of the patient's response to the therapy given [11].

The analysis of RANKL expression is typically expensive and not easily accessible. The 
Neutrophil-Lymphocyte Ratio (NLR), an indicator of systemic inflammation, and lactate dehydrogenase $(\mathrm{LDH})$, an enzyme that is upregulated during osteoclast differentiation, were proposed as markers that are associated with RANKL in patients with MBD. This study was conducted to identify the correlations of RANKL expression, LDH, and NLR levels in patients with bone metastatic lesions.

\section{Methods}

This descriptive-analytical study with a crosssectional design was conducted from January 2019 to December 2019 at Dr. Sardjito Hospital and Faculty of Medicine, Public Health and Nursing, Universitas Gadjah Mada (UGM). Subjects that met the inclusion criteria were consecutively included for this study. The subjects were patients diagnosed with MBD based on physical evaluation and radiological examination. Patients with primary bone tumor, and history of chemotherapy and/or radiotherapy were not included in this study. Patients who refused to participate were also excluded from the study. This study was approved by the appropriate Institutional Review Board Committee with ethical clearance number KE/FK/0739/EC/2019.

\section{Sample collection and extraction}

Bone samples were obtained via open biopsy in the metastatic lesions' region. Half of the samples were sent to Anatomical Pathology Laboratory for definitive diagnosis and the rest stored in biobank facility of UGM for molecular analysis. Control samples were obtained from patients with non-pathological fractures. The blood samples were taken in the range of 1-7 days before surgery and the evaluation of complete blood count, differential leukocyte count, LDH counts (U/L), and NLR were performed.

Fresh bone samples were washed with normal saline, put in the liquid nitrogen and then crushed into powder in a mortar. The powder was transferred in a $1.5 \mathrm{ml}$ tube and homogenized with $1 \mathrm{ml}$ Trizole. Homogenates were then centrifuged at $10,000 \mathrm{rpm}$ for $10 \mathrm{~min}$ at $4^{\circ} \mathrm{C}$ to remove insoluble material. The supernatant product was mixed into $200 \mu \mathrm{L}$ chloroform, soaked in ice for $15 \mathrm{~min}$, then centrifuged at a speed of $13,200 \mathrm{rpm}$ for $20 \mathrm{~min}$ at $4^{\circ} \mathrm{C}$. Liquid RNA was then precipitated with $500 \mu \mathrm{L}$ isopropanol and then stored for $30 \mathrm{~min}$ at $-20^{\circ} \mathrm{C}$ and centrifuged again at $13,200 \mathrm{rpm}$ for $20 \mathrm{~min}$ at $4^{\circ} \mathrm{C}$ to obtain the pellet shape. RNA pellets were washed with $75 \%$ ethanol, dried in the room temperature and resuspended in RNasefree water. The RNA concentration was measured by spectrophotometry at a ratio of $260 \mathrm{~nm}$ and the purity of the RNA was assessed at a ratio of $260-280 \mathrm{~nm}$.

\section{Quantitative reverse transcription- polymerase chain reaction (RT-PCR)}

cDNA was synthesized from total RNA samples using High Capacity RNA to cDNA Kit (LOT 00788700). The reaction used $1 \mu \mathrm{g}$ of bone RNA and was incubated in Pro Flex PCR System (Applied Biosystem, Thermo Fisher Scientific) initially at $25^{\circ} \mathrm{C}$ for $10 \mathrm{~min}$, then at $37^{\circ} \mathrm{C}$ for $120 \mathrm{~min}$, and finally at $85^{\circ} \mathrm{C}$ for $5 \mathrm{~min}$. Gene expression was determined by quantitative RT-PCR using TaqMan probe-based chemistry. Reactions were performed in 96 well plates on qPCR 7500FAST (Thermo Fisher Scientific). TaqMan probes and PCR primer were obtained from Life Technology (TaqMan Gene Expression Assay) Hs002243522_m1 for TNFSF11 (RANKL). Glyceraldehyde 3-phosphate dehydrogenase (Life technology, part no 4332649f) was used as housekeeping gene. The amplification was performed using Platinum DNA polymerase High Fidelity, Invitrogen (Thermo Fisher Scientific) using the following conditions: 1 cycle of $50^{\circ} \mathrm{C}$ for $2 \mathrm{~min}$ and $95^{\circ} \mathrm{C}$ for $5 \mathrm{~min}$; followed by 40 cycles of $95^{\circ} \mathrm{C}$ for $15 \mathrm{~s}$ and $60^{\circ} \mathrm{C}$ for $1 \mathrm{~min}$.

\section{Statistical analysis}

The result was then statistically analyzed using SPSS software, version 11.5 (SPSS, Inc., Chicago, IL, USA). Homogeneity test was done using Saphiro Wilk tests. Correlation between two variables was analyzed with Spearman correlation analysis. One-way analysis of variant (ANOVA) was used to compare multiple groups and least significant difference t-test was used to compare two groups using means and standard deviation, with $p<0.05$ was considered as a statistically significant difference.

\section{Results}

This study involved 15 subjects with primary malignancy of solid organs that had metastasized to the bones. All subjects were women, with an average age of 54.56 years. In all 15 subjects (100\%), indistinct lesion margins were observed. Most metastatic lesions were found in bone metaphysis (60\%), with $13(86.7 \%)$ metastatic lesions which were lytic lesions, and $14(93.3 \%)$ which were in broad transition zones. This study found the mean LDH level was $416.94 \pm 139.74$ and the NLR was $7.60 \pm 4.20$. The mean of RANKL expression was $6.33 \pm 1.16$. Breast cancer was the majority of cases (8 subjects), with the mean RANKL expression of $6.34( \pm 0.92)$. RANKL expression in patients with pulmonary cancer was 6.91 , cervical cancer 5.14, thyroid cancer 5.40 , colon cancer 6.34 , and liver cancer 9.11, as shown in Figure 1. 


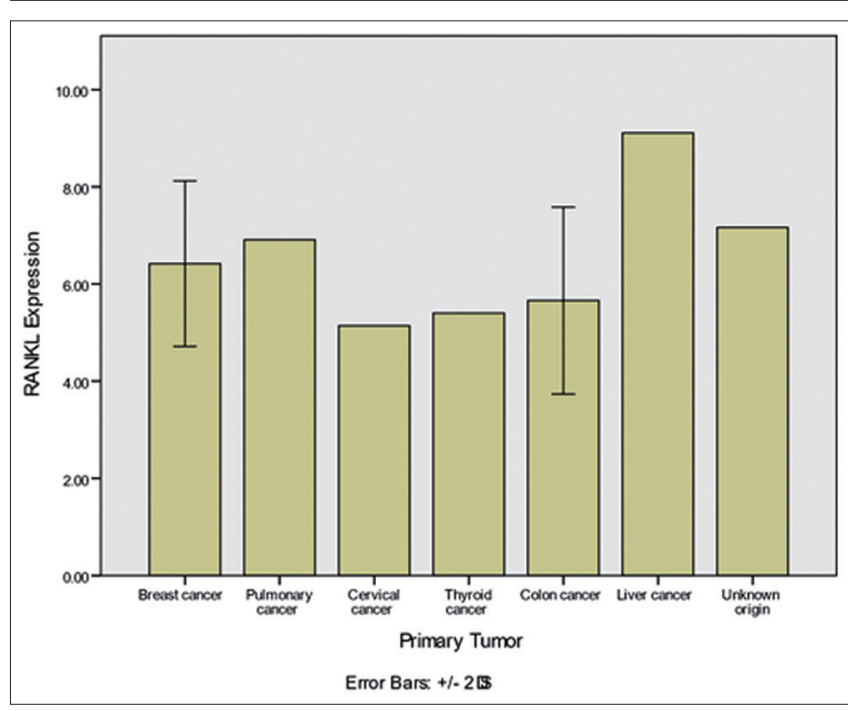

Figure 1: Receptor activator of nuclearfactor $k \beta$ ligand expression based on primary tumor origin

The mean expression of RANKL in normal control subjects was $4.94 \pm 0.12$, with the mean of serum LDH of $246.5 \pm 33.5$ and NLR of $3.87 \pm 0.89$. Meanwhile, in subjects with bone metastasis, the RANKL expression was $6.43 \pm 1.13$; the mean of serum $\mathrm{LDH}$ level was $429.33 \pm 135.23$, and the NLR was $6.96 \pm 3.44$.

The Mann-Whitney test was performed to determine differences in the two groups and showed that RANKL expression in the patients with bone metastasis was higher than in the control ( $p$ : 0.009). Statistical analysis using Mann-Whitney revealed that LDH levels in the bone metastatic patients was higher than controls ( $p: 0.04$ ), while NLR was higher in the bone metastatic patients, compared to controls ( $p$ : 0.028). The Pearson Correlation statistical test was evaluated to determine the correlation between RANKL expression and the subject's age. A positive correlation was found with the strength of very weak correlation between age with the RANKL expression but it was not statistically significant with a p: 0.795 (r: 0.071) (Figure 2).

This study also analyzed various characteristics of bone metastatic lesions with the RANKL expression.
The unpaired t-test showed there was no correlation between RANKL expression and the lesion type (p: 0.167). No association was found between the area of the transition zone and the RANKL expression in the unpaired difference t-test ( $p$ : 0.557). The one-way ANOVA test showed there was no significant difference in the mean RANKL expression at the location of bone metastatic lesions ( $p$ : 0.313). The relationship between characteristics of bone metastatic lesions with RANKL expression is presented in Table 1.

Correlation between serum LDH levels with RANKL expression was analyzed using Pearson Correlation test and revealed a significant positive correlation with a p: 0.028, (r: 0.547) as seen in Figure 2.

Correlation between NLR with the RANKL expression was analyzed using the Pearson Correlation test and revealed a significant negative correlation with a p: $0.029(r$ : -0.545) (Figure 2). The correlation analysis of RANKL expression with age, LDH level, and NLR is summarized in Table 2.

\section{Discussion}

The majority of malignancies in solid organs can cause osteolytic metastatic lesions in the bone. Patients with solid organ malignancies, such as breast or lung cancers, which have metastasized to the bone, usually form lytic lesions that can be seen radiologically due to the response to bone damage caused by the process of new bone formation [6]. Lytic lesions are actually formed by the osteolysis process initiated by osteoclast activity, not the result of the activity of cancer cells themselves [12].

This study showed $60 \%$ of subjects had metastatic lesions in bone metaphysis. Metaphysis of the bones has large sinusoid and slow blood flow that allow intimate interactions between tumor cells and endothelium, leading to early colonization of tumor cells in the bone marrow [13]. However, this study failed
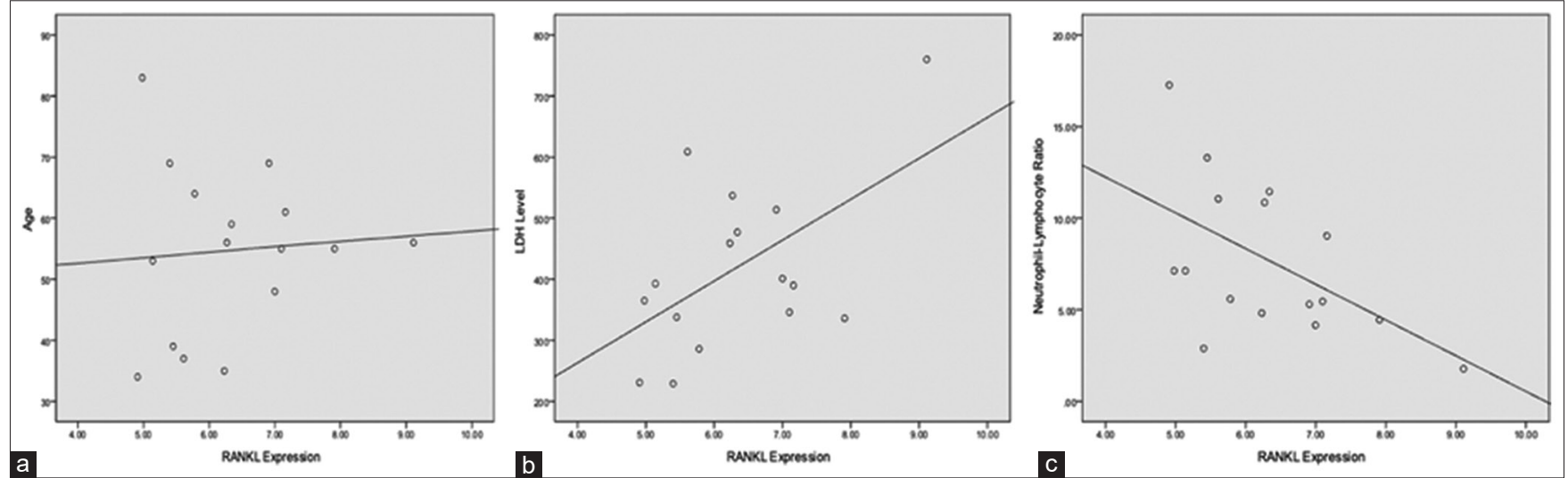

Figure 2: Correlation between Age (a), lactate dehydrogenase levels (b), and neutrophil and lymphocyte ratio (c) with receptor activator of nuclearfactor $\mathrm{k} \beta$ ligand expression 
to reveal any association between RANKL expression with age and other metastatic lesion characteristics.

Table 1: RANKL expression in metastatic lesions

\begin{tabular}{llc}
\hline Characteristics of metastatic lesion (N) & RANKL expression & $\mathrm{p}$ \\
\hline Type of lesion & & \\
$\quad$ Lytic (13) & $6.59 \pm 1.12$ & $0.167 \mathrm{a}$ \\
$\quad$ Mixed (2) & $5.38 \pm 0.57$ & \\
Location & & $0.313 \mathrm{~b}$ \\
$\quad$ Epiphysis (1) & 7.16 & \\
$\quad$ Metaphysis (9) & $6.08 \pm 0.64$ & \\
$\quad$ Diaphysis (5) & $6.91 \pm 1.71$ & \\
Border & $6.33 \pm 1.16$ & $0.557 \mathrm{a}$ \\
$\quad$ III defined (15) & & \\
Transition zone & $6.38 \pm 1.16$ & \\
$\quad$ Wide (14) & 7.10 & \\
$\quad$ Narrow (1) &
\end{tabular}

RANKL is a protein that is bound to the surface of osteoblast cell membranes and bone marrow cell stroma. When RANKL binds to RANK on the surface of osteoclast precursors, it causes stimulation of differentiation of these precursor cells to mature osteoclasts [14]. This study showed that the presence of RANKL must be present in the formation of osteolytic bone lesions [10]. Moreover, the blockade of RANKRANKL interactions causes inhibition of osteolytic lesion formation in several types of cancers [15], [16].

Table 2: Correlation of RANKL expression with age, LDH level, and NLR

\begin{tabular}{lll}
\hline & \multicolumn{2}{l}{ RANKL levels } \\
\cline { 2 - 3 } & $\mathrm{r}$ & $\mathrm{p}$ \\
\hline Age & 0.071 & 0.795 \\
LDH levels (U/L) & 0.547 & 0.028 \\
Neutrophil-Lymphocyte Ratio (NLR) & -0.545 & 0.029 \\
\hline
\end{tabular}

Association between the characteristics of metastatic lesions with RANKL expression was not found in this study. The characteristics of MBD lesions were affected by specific cytokines secreted by tumor cells while RANKL is necessary for the development of osteolytic lesion in bone and more influenced by the process of bone metabolism. RANKL promotes bone resorption by osteoclasts and prevents apoptosis [17].

This study revealed that serum LDH levels in patients with bone metastasis was high. Increased levels of LDH in patients with bone metastasis have been widely reported. Conen et al. reported that elevated serum LDH levels were associated with risk of bone metastasis in patients with small-cell lung cancer, with LDH levels $\geq 300$ and $\geq 1000$ were associated with the incidence of bone metastases with odds ratio (OR) 3.75 (1.46-9.63), and OR 5.63 (1.02-31.07), respectively [18]. Similar study by Katakami et al. also stated that serum LDH levels $\geq 1000$ was a predictor factor for bone metastasis with HR 9.14 (1.51-55.14) [19].

A previous study demonstrated that during RANKL-stimulated osteoclast differentiation, there is a metabolic shift in which glycolysis and mitochondrial respiration are increased to allow differentiation of osteoclast precursors into mature ones. LDH is a tetrameric enzyme formed by subunit $A$ and/or subunit $B$ that plays a major role in glycolysis catalyzing the exchange of pyruvate to lactate [20]. Thus, it is possible that an increase in the osteoclastic process will be followed by elevated LDH levels. This explains our finding that LDH levels are significantly correlated with RANKL expression.

The correlation between the NLR with RANKL expression was not significant in this study. A study conducted by Caliskan et al. reported that NLR was significantly higher in the patients with bone metastasis. Neutrophils are hypothesized to have a role in tumor angiogenesis by producing proangiogenic factors [21]. Increased neutrophils and decreased lymphocytes count play a role in increasing NLR. Several studies have found that an increase in NLR is associated with a worse prognosis in patients with bone metastatics [11], [21], [22].Inflammatory conditions mainly play a role in angiogenesis, mutations, cell migration, and metastasis. Based on this understanding, previous study showed that the inflammatory process can be used as a predictor of metastasis and outcome in patients with bone metastasis [11], [23].

A study conducted by Huang, involving a population of women with osteoporosis, revealed that in the process of osteoporosis an increase in proinflammatory cytokines and NLR occurs. The relationshipbetween inflammation inosteoporosismainly occurs through the RANK/RANKL/osteoprotegerin (OPG) pathway [24]. The same finding was confirmed by Ozturk et al. showing patients with osteoporosis had a higher increase in the NLR ratio than in patients with osteopenia or the normal population [25]. The study revealed that pro-inflammatory markers influence mesenchymal stem cells and osteoclast precursors in increasing osteoclast-mediated bone resorption. On the other hand, it is known that cell interactions between RANK-RANKL stimulate osteoclast differentiation from its precursor cells. RANKL also supports osteoclast activity in bone absorption and prevents cell death [23], [25]. The NLR was associated as a prognostic factor in the success of therapy or survival in various types of malignancies, including MBD. A higher NLR was associated with a worse prognosis, while RANKL expression was more associated with the occurrence of metastatic bone lesion [11], [21], [22]. In line with this, RANKL was associated with a better therapeutic response, i.e. an increase of 1 unit of RANKL increases 2.5 times the likelihood of a patient response to a given therapy [26]. The result of this study supports the theory that RANKL can be used to further determine the need of prophylactic fixation and osteoclastic agent in the management of MBD.

This study has some limitations including small research subjects due to study's time constraints and no measurement of other markers associated with metastatic lesions in bone such as OPG. Increase the number of research sample in subsequent study would be beneficial to obtain better picture of RANKL correlation with LDH and NLR in metastasis bone disease in population. 


\section{Conclusion}

This study revealed that RANKL expression was positively correlated with LDH and negatively correlated with the NLR. In bone metastasis case, both LDH and NLR can be used as predictive factors of RANKL expression.

\section{Acknowledgment}

We thank Sri Fatmawati, a laboratory technician, in the Integrated Laboratory of Faculty of Medicine, Public health and Nursing, UGM, for the great assistance while this study was conducted.

\section{References}

1. Nayir E. Pathogenesis of bone metastasis. J Oncol Sci. 2016;1:13-6.

2. Bussard KM, Gay CV, Mastro AM. The bone microenvironment in metastasis; what is special about bone? Cancer Metastasis Rev. 2008;27(1):41-55. https://doi.org/10.1007/s10555-007-9109-4 PMid:18071636

3. Coleman RE, Rubens RD. The clinical course of bone metastases from breast cancer. Br J Cancer. 1987;55(1):61-6. https://doi.org/10.1038/bjc.1987.13

PMid:3814476

4. Mundy GR. Metastasis to bone: Causes, consequences and therapeutic opportunities. Nat Rev Cancer. 2002;2(8):584-93. https://doi.org/10.1038/nrc867

PMid:12154351

5. Narayanan P. Denosumab: A comprehensive review. South Asian J Cancer. 2013;2(4):272-7. https://doi. org/10.4103/2278-330X.119895

PMid:24455656

6. Roodman GD. Mechanisms of bone metastasis. N Engl J Med 2004;350(16):1655-64. https://doi.org/10.1056/NEJMra030831 PMid:15084698

7. Chung PL, Zhou S, Eslami B, Shen L, LeBoff MS, Glowacki J. Effect of age on regulation of human osteoclast differentiation. J Cell Biochem. 2014;115(8):1412-9. https://doi.org/10.1002/ jcb.24792

\section{PMid:24700654}

8. Lacey DL, Boyle WJ, Simonet WS, Kostenuik PJ, Dougall WC Sullivan JK, et al. Bench to bedside: Elucidation of the OPGRANK-RANKL pathway and the development of denosumab. Nat Rev Drug Discov. 2012;11(5):401-19. https://doi. org/10.1038/nrd3705

\section{PMid:22543469}

9. Huang L, Cheng YY, Chow LT, Zheng MH, Kumta SM. Tumour cells produce receptor activator of NF-KB ligand (RANKL) in skeletal metastases. J Clin Pathol. 2002;55(11):877-8. https:// doi.org/10.1136/jcp.55.11.877

PMid:12401833
10. Kitazawa S, Kitazawa R. RANK ligand is a prerequisite for cancerassociated osteolytic lesions. J Pathol. 2002;198(2):228-36. https://doi.org/10.1002/path.1199

PMid:12237883

11. Vano YA, Oudard S, By MA, Têtu P, Thibault C, Aboudagga $H$, et al. Optimal cut-off for neutrophil-to-lymphocyte ratio: Fact or fantasy? A prospective cohort study in metastatic cancer patients. PLoS One. 2018;13(4):e0195042. https://doi. org/10.1371/journal.pone.0195042.

PMid:29624591

12. Rove KO, Crawford ED. Metastatic cancer in solid tumors and clinical outcome: Skeletal-related events. Oncology. 2009;23 Suppl 14:21-7. PMid:20128325

13. Virk MS, Lieberman JR. Tumor metastasis to bone. Arthritis Res Ther. 2007;9 Suppl 1:S5. https://doi.org/10.1186/ar2169 PMid:17634144

14. Peng X, Guo W, Ren T, Lou Z, Lu X, Zhang S, et al. Differential expression of the RANKL/RANK/OPG system is associated with bone metastasis in human non-small cell lung cancer. PLoS One. 2013;8(3):e58361. https://doi.org/10.1371/journal. pone. 0058361

PMid:23516466

15. Whang PG, Schwarz EM, Gamradt SC, Dougall WC Lieberman JR. The effects of RANK blockade and osteoclast depletion in a model of pure osteoblastic prostate cancer metastasis in bone. J Orthop Res. 2005;23(6):1475-83. https:// doi.org/10.1016/j.orthres.2005.05.004.1100230634 PMid: 16005175

16. Cao J, Venton L, Sakata T, Halloran BP. Expression of RANKL and OPG correlates with age-related bone loss in male C57BL/6 mice. J Bone Miner Res. 2003;18(2):270-7. https://doi. org/10.1359/jbmr.2003.18.2.270 PMid:12568404

17. Roodman GD. Regulation of osteoclast differentiation. Ann NY Acad Sci. 2006;1068(1):100-9. https://doi.org/10.1196/ annals. 1346.013

PMid: 16831910

18. Conen K, Hagmann R, Hess V, Zippelius A, Rothschild SI Incidence and predictors of bone metastases (BM) and skeletalrelated events (SREs) in small cell lung cancer (SCLC): A Swiss patient cohort. J Cancer. 2016;7(14):2110-6. https://doi. org/10.7150/jca.16211

PMid:27877227

19. Katakami N, Kunikane H, Takeda K, Takayama K, Sawa T, Saito $\mathrm{H}$, et al. Prospective study on the incidence of bone metastasis (BM) and skeletal-related events (SREs) in patients (pts) with stage IIIB and IV lung cancer-CSP-HOR 13. J Thorac Oncol. 2014;9(2):231-8. https://doi.org/10.1097/ JTO.0000000000000051

PMid:24419421

20. Ahn H, LeeK, Kim JM, Kwon SH, LeeSH, LeeSY, etal.Accelerated lactate dehydrogenase activity potentiates osteoclastogenesis via NFATc1 signaling. PLoS One. 2016;11(4):e0153886. https:// doi.org/10.1371/journal.pone. 0153886

PMid:27077737

21. Caliskan B, Korkmaz AN. Can neutrophil/lymphocyte ratio be a predictor for bone metastases of solid tumors? World J Nucl Med. 2016;15(3):196-9. https://doi.org/10.4103/1450-1147.174711 PMid:27651741

22. Thio QC, Goudriaan WA, Janssen SJ, Pereira NR, Sciubba DM, Rosovksy RP, et al. Prognostic role of neutrophil-to-lymphocyte ratio and platelet-to-lymphocyte ratio in patients with bone metastases. $\mathrm{Br} J$ Cancer. 2018;119(6):737-43. https://doi. org/10.1038/s41416-018-0231-6 
PMid:30116026

23. Roxburgh CS, McMillan DC. Role of systemic inflammatory response in predicting survival in patients with primary operable cancer. Future Oncol. 2010;6(1):149-63. https://doi.org/10.2217/ fon.09.136

PMid:20021215

24. Huang C, Li S. Association of blood neutrophil lymphocyte ratio in the patients with postmenopausal osteoporosis. Pak J Med Sci. 2016;32(3):762-5. https://doi.org/10.12669/ pjms.323.10292

PMid:27375729
25. Öztürk ZA, Yesil Y, Kuyumcu ME, Bilici M, Öztürk N, Yeşil NK, et al. Inverse relationship between neutrophil lymphocyte ratio (NLR) and bone mineral density (BMD) in elderly people. Arch Gerontol Geriatr. 2013;57(1):81-5. https://doi.org/10.1016/j. archger.2013.02.005

PMid:23490023

26. Ibrahim T, Ricci M, Scarpi E, Bongiovanni A, Ricci R, Riva N, et al. RANKL: A promising circulating marker for bone metastasis response. Oncol Lett. 2016;12(4):2970-5. https://doi. org/10.3892/ol.2016.497

PMid:27698885 